\title{
Expressive aphasia in a patient with chronic myelomonocytic leukemia
}

\author{
Darwin F Yeung ${ }^{1 *}$ and Rose Hsu,
}

\begin{abstract}
Various paraneoplastic autoimmune phenomena have been reported in patients with myelodysplastic syndromes. We describe a patient who developed expressive aphasia as a paraneoplastic complication of chronic myelomonocytic leukemia (CMML). Awareness of the various possible manifestations of CMML may aid in the early recognition of the condition.
\end{abstract}

Keywords: Chronic myelomonocytic leukemia; Paraneoplastic syndromes; Autoimmunity; Aphasia

\section{Background}

Chronic myelomonocytic leukemia (CMML) is a clonal hematopoietic stem cell disorder that exhibits both myelodysplastic and myeloproliferative features and is characterized by persistent absolute monocytosis (Parikh and Tefferi 2013). Median survival ranges from 10 to 32 months (Patnaik et al. 2013). Diagnosis may be aided by awareness of its various manifestations, including autoimmune paraneoplastic phenomena (Saif et al. 2002; Enright et al. 1995; Craig and Lin 2013; Fleming et al. 2012; Lemasle et al. 2010; Messiaen et al. 1996). We describe a patient with expressive aphasia as the presenting symptom of CMML.

\section{Case description}

A 64-year-old previously healthy woman presented to hospital in October 2011 with loss of consciousness, expressive aphasia, and left lower extremity numbness. Exam revealed left lower extremity involuntary movements as well as fluent aphasia with paraphasic errors, impaired comprehension, impaired reading, and preserved writing. Computed tomography $(\mathrm{CT})$, magnetic resonance imaging (MRI), and electroencephalography (EEG) were unremarkable. Her symptoms resolved without intervention within days. She began a trial of phenytoin for presumed seizures but discontinued it shortly after discharge due to intolerance.

\footnotetext{
* Correspondence: darwin.yeung@alumni.ubc.ca

${ }^{1}$ Department of Medicine, University of British Columbia, 2775 Laurel Street, 10th Floor, Vancouver, BC V5Z 1M9, Canada

Full list of author information is available at the end of the article
}

That admission, she demonstrated microcytic anemia (hemoglobin $8.8 \mathrm{~g} / \mathrm{dL}$ (range 12.0-15.0), mean corpuscular volume (MCV) $74 \mathrm{fL}$ (range 82-98)), thrombocytopenia (platelet count $107 \times 10^{9} / \mathrm{L}$ (range 150-400)), normal white blood cell (WBC) count $\left(7.4 \times 10^{9} / \mathrm{L}\right.$ (range 4.0$10.5)$ ) and monocytosis $\left(1.10 \times 10^{9} / \mathrm{L}\right.$ (range $\left.0.10-0.80\right)$ ). Her anemia had been present for over a decade but had not been investigated by a bone marrow biopsy.

Four months later, she re-presented with aphasia, confusion, headache, and left-sided numbness that gradually resolved without intervention. She lost $18 \mathrm{~kg}$ since her last admission. CT, MRI, and EEG now showed a subacute left cerebellar infarct but no other abnormalities. Investigations revealed persistent microcytic anemia, thrombocytopenia, and monocytosis, along with neutrophilia $\left(6.99 \times 10^{9} / \mathrm{L}\right.$, range $\left.2.00-6.00\right)$ and an enlarged spleen $(13.5 \times 13 \times 11 \mathrm{~cm})$. A bone marrow biopsy and cytogenetic analysis demonstrated panhyperplasia and no detectable clonal abnormality. She was discharged on gabapentin for presumed seizures.

Two months later, her aphasia returned with accompanying pericardial effusion, biopsy-proven leptomeningeal inflammation, and left elbow arthritis responsive to prednisone. Rheumatoid factor was transiently elevated at $21.8 \mathrm{IU} / \mathrm{mL}$ (range 0.0-20.0). She developed severe leukocytosis (WBC $75.1 \times 10^{9} / \mathrm{L}$ ) from neutrophilia $\left(54.82 \times 10^{9} / \mathrm{L}\right)$ and monocytosis $\left(11.26 \times 10^{9} / \mathrm{L}\right)$. However, repeat bone marrow biopsy revealed only reactive hyperplasia. Her gapapentin was replaced with valproic acid, methotrexate, and a tapering dose of prednisone.

\section{勿}


Over the next 18 months, she had no further recurrences of aphasia but failed to thrive due to an enlarging spleen $(25 \times 16 \times 12 \mathrm{~cm})$. A third bone marrow biopsy in September 2013, after two years of investigation, demonstrated CMML. She started hydroxyurea to reduce the size of her spleen and discontinued prednisone and methotrexate given her neurological remission.

Two months after diagnosis, she was re-admitted for a fourth episode of aphasia that resolved after the reinstitution of prednisone. Given the substantial morbidity from her massive spleen, she underwent a splenectomy. Unfortunately, she developed respiratory failure due in part to leukostasis (WBC $253.4 \times 10^{9} / \mathrm{L}$ ) and died on the second post-operative day.

\section{Discussion}

To our knowledge, this is the first reported case of CMML presenting with expressive aphasia. Its recurrence during disease progression along with its responsiveness to steroids support it being a paraneoplastic autoimmune complication. Previously reported neurologic manifestations of CMML include Guillain-Barre syndrome (del Campo Fernández et al. 2001), IgA-related polyneuropathy (Maeda et al. 1989), and acute and chronic inflammatory demyelinating polyneuropathies (Konstadoulakis et al. 1993; Isoda et al. 2009) peripherally, as well as seizures (Enright et al. 1995), right hemiparesis (Takubo et al. 1998), meningeal inflammation (Aoyama et al. 2003; Ohno et al. 1988), suprachoroidal hemorrhage (Shaikh et al. 2002), pseudotumor inflammatory lesions (Joubert et al. 2013), and anterior ischemic optic neuropathy (De Smit and O'Sullivan 2013) centrally. Awareness of the various manifestations of the condition, including aphasia, however rare, will hopefully alert clinicians of CMML as a diagnostic possibility.

\section{Consent}

Written informed consent was obtained from the patient's next of kin for the publication of this report.

\section{Competing interests}

The authors declare they have no competing interests.

\section{Authors' contributions}

DY and RH drafted the manuscript. Both authors read and approved the final manuscript.

\section{Acknowledgements}

The authors thank Dr. Stephen N. Sullivan for his review of the manuscript.

\section{Author details}

'Department of Medicine, University of British Columbia, 2775 Laurel Street, 10th Floor, Vancouver, BC V5Z 1M9, Canada. ${ }^{2}$ Island Medical Program, University of Victoria, Victoria, BC, Canada.

\section{References}

Aoyama K, Ishikura H, Tsumura H, Watanabe T, Suyama N, Kumakura S, Kobayashi S (2003) Meningeal involvement of chronic myelomonocytic leukemia. J Neurol 250:993-994

Craig JW, Lin RJ (2013) Paraneoplastic autoimmunity associated with testicular myeloid sarcoma and chronic myelomonocytic leukemia. Case Rep Hemato 2013:656543

De Smit E, O'Sullivan E (2013) A diagnostic challenge: chronic myelomonocytic leukaemia and recurrent anterior ischaemic optic neuropathy. Int Ophthalmol 33:415-423

del Campo Fernández R, Polo Zarzuela M, del Portillo Prieto I, Poyo-Guerrero Lahoz $R$ (2001) Chronic myelomonocytic leukemia presenting as Guillain- Barré syndrome. Med Clin (Barc) 116:797

Enright H, Jacob HS, Vercellotti G, Howe R, Belzer M, Miller W (1995) Paraneoplastic autoimmune phenomena in patients with myelodysplastic syndromes: response to immunosuppressive therapy. Br J Haematol 91:403-408

Fleming S, Hellström-Lindberg E, Burbury K, Seymour JF (2012) Paraneoplastic large vessel arteritis complicating myelodysplastic syndrome. Leuk Lymphoma 53:1613-1616

Isoda A1, Sakurai A, Ogawa Y, Miyazawa Y, Saito A, Matsumoto M, Sawamura M (2009) Chronic inflammatory demyelinating polyneuropathy accompanied by chronic myelomonocytic leukemia: possible pathogenesis of autoimmunity in myelodysplastic syndrome. Int J Hematol 90:239-242

Joubert B, Desestret V, Rheims S (2013) Brain pseudo-tumoral inflammatory lesion associated with chronic myelomonocytic leukemia. J Neurooncol 113:149-150

Konstadoulakis MM, Papasavvas P, Bitsaktis A, Voumvourakis C, Davaki P Papageorgiou C (1993) Acute demyelinating peripheral neuropathy in a patient with double monoclonal gammopathy and chronic myelomonocytic leukemia. Muscle Nerve 16:431-432

Lemasle E, Jardin F, Duval AB, Courville P, Buchonnet G, Callat MP, Stamatoullas A, Tilly H (2010) Miescher cheilitis and myelomonocytic leukemia: a fortuitous association or a rare paraneoplastic syndrome? Leuk Lymphoma 51:730-732

Maeda T, Ashie T, Kikuiri K, Ishiyama N, Takakura M, Ise T (1989) Chronic myelomonocytic leukemia with polyneuropathy and IgA-paraprotein. Jpn J Med 28:709-716

Messiaen T, Lefebvre C, Lambert M (1996) Case report: thoracic aorta thrombus with systemic embolization: a rare paraneoplastic antiphospholipid syndrome? Am J Med Sci 312:303-305

Ohno Y, Kamesaki H, Amano H, Imanaka T, Takahashi Y, Ichijima K, Hayashi T (1988) Meningeal leukemia in the chronic stage of chronic myelomonocytic leukemia. Rinsho Ketsueki 29:901-906

Parikh SA, Tefferi A (2013) Chronic myelomonocytic leukemia: 2013 update on diagnosis, risk stratification, and management. Am J Hematol 88:967-974

Patnaik MM, Padron E, LaBorde RR, Lasho TL, Finke CM, Hanson CA, Hodnefield JM, Knudson RA, Ketterling RP, Al-kali A, Pardanani A, Ali NA, Komrokji RS, Tefferi A (2013) Mayo prognostic model for WHO-defined chronic myelomonocytic leukemia: ASXL1 and spliceosome component mutations and outcomes. Leukemia 27:1504-1510

Saif MW, Hopkins JL, Gore SD (2002) Autoimmune phenomena in patients with myelodysplastic syndromes and chronic myelomonocytic leukemia. Leuk Lymphoma 43:2083-2092

Shaikh A, Parulekar M, James B (2002) Acute suprachoroidal haemorrhage with acute angle closure glaucoma as a presenting sign of chronic myelomonocytic leukemia. Eye 16:651-653

Takubo H1, Hattori N, Irie S, Mizutani Y, Mori H, Suda K, Kondo T, Oshimi K, Mizuno Y (1998) A 45-year-old man with peripheral monocytosis and right hemiparesis. No To Shinkei 50:481-489

doi:10.1186/2193-1801-3-406

Cite this article as: Yeung and Hsu: Expressive aphasia in a patient with chronic myelomonocytic leukemia. SpringerPlus 2014 3:406. 